\title{
SISTEM INFORMASI GEOGRAFIS PENYEBARAN USAHA MIKRO, KECIL DAN MENENGAH BERBASIS WEB
}

\author{
Melinawati $^{1}$, Hendra Di Kesuma ${ }^{2}$ \\ ${ }^{1}$ Sistem Informasi, STMIK Bina Nusantara Jaya Lubuklinggau \\ Jalan Yos Sudarso Kota Lubuklinggau Sumatera Selatan \\ ${ }^{2}$ Manajemen Informatika, Universitas IGM Palembang \\ Jl. Jend. Sudirman KM.4 No.629 Kota Palembang Sumatera Selatan \\ E-mail :melinawati13@gmail.com ${ }^{1}$,hendra.dikesuma@gmail.com²
}

\begin{abstract}
UMKM (Usaha Mikro Kecil dan Menengah) is a businessman engaged in several business areas, which touches the public interest. This information needs not only a necessity for the Office of Cooperatives, UMKM and market management Lubuklinggau but becomes broader community needs. For dissemination of geographic information that can be accessed from anywhere and at any time, the system this information is presented in a web form. many UMKM are scattered deployment Lubuklinggau then these institutions need a geographical information system that shows the region - the region which are UMKM based on data from districts. With the construction of geographic information system, then the Department of Cooperatives UMKM and market management will be greatly assisted in providing information to the public about the location of the spread of UMKM, location of the region and its spread
\end{abstract}

Keywords: Geographic Information Systems, Distribution of UMKM, MapInfo.

\begin{abstract}
Abstrak
UMKM (Usaha Mikro Kecil dan Menengah) merupakan pelaku bisnis yang bergerak dibeberapa bidang usaha, yang menyentuh kepentingan masyarakat. Kebutuhan informasi ini tidak hanya menjadi kebutuhan bagi pihak Kantor Dinas Koperasi, UMKM dan Pengelolaan Pasar Kota Lubuklinggau tetapi menjadi kebutuhan masyarakat secara luas. Untuk tujuan penyebaran informasi geografis yang dapat diakses dari mana saja dan kapan saja maka sistem informasi ini disajikan dalam bentuk web. banyaknya penyebaran UMKM yang tersebar di Kota Lubuklinggau maka Instansi ini membutuhkan suatu sistem informasi geografis yang menunjukan kawasan - kawasan yang terdapat UMKM berdasarkan data kecamatan. Dengan dibangunnya sistem informasi geografis, maka pihak Dinas Koperasi UMKM dan Pengelolaan Pasar akan sangat terbantu dalam memberikan informasi kepada masyarakat tentang lokasi penyebaran UMKM, letak wilayah dan penyebarannya..
\end{abstract}

Kata kunci: Sistem Informasi Geografis, UMKM, Mapinfo.

\section{Pendahuluan}

UMKM merupakan kelompok pelaku ekonomi terbesar dalam perekonomian indonesia dan terbukti menjadi katup pengaman perekonomian nasional dalam masa krisis, serta menjadi dinamisator pertumbuhan ekonomi pasca krisis ekonomi. Selain menjadi sektor usaha yang paling besar kontibusinya terhadap pembangunan nasional, UMKM juga menciptakan peluang kerja yang cukup besar bagi tenaga kerja dalam negeri, sehingga membantu upaya mengurangi pengangguran.[1]

UMKM telah diatur secara hukum melalui Undang Undang Nomor 20 Tahun 2008 tentang Usaha Mikro Kecil dan Menengah. Kebutuhan informasi ini tidak hanya menjadi kebutuhan bagi pihak Kantor Dinas Koperasi, UMKM dan Pengelolaan Pasar Kota Lubuklinggau tetapi menjadi kebutuhan masyarakat secara luas. Untuk tujuan penyebaran informasi geografis yang dapat diakses dari mana saja dan kapan saja maka sistem informasi ini disajikan dalam bentuk web yang ditampilkan melalui internet. Berkaitan dengan UMKM, maka informasi geografis akan berisi mengenai lokasi dan informasi yang terdapat UMKM pada setiap wilayah yang ada di Kota Lubuklinggau. Perubahan yang terjadi kapan saja pada UMKM berkaitan dengan penambahan dan pengurangan data akan dapatdilakukan secara update tanpa harus membuat baru.

Dinas Koperasi Usaha Mikro Kecil dan Menengah Merupakan sebuah instansi pemerintah yang dibentuk berdasarkan peraturan daerah nomor 13 tahun 2003 tanggal 16 juni 2003. Adapun maksud dan tujuan di bentuknya Dinas Koperasi Usaha Mikro kecil dan Menengah adalah untuk membina koperasi usaha kecil dan menengah agar dapat tumbuh dan berkembang menjadi badan usaha yang kokoh dan mandiri serta meningkatkan efisiensi pasar sebagai ekonomi daerah dan meningkatkan pendapatan asli daerah dari pengelolaan pasar.

Kendala yang terjadi di Kantor Dinas Koperasi UMKM dan Pengelolaan Pasar khususnya bidang UMKM yaitu belum adanya pemetaan untuk menampilkan lokasi, wilayah dan kawasan-kawasan penyebaran UMKM, banyaknya penyebaran UMKM yang tersebar di Kota Lubuklinggau maka Instansi ini membutuhkan suatu sistem informasi geografis yang menunjukan kawasan kawasan yang terdapat UMKM berdasarkan data kecamatan, Dengan dibangunnya sistem informasi geografis, maka pihak Dinas Koperasi UMKM dan 
Pengelolaan Pasar akan sangat terbantu dalam Sehingga petugas bidang UMKM hanya mengetahui memberikan informasi kepada masyarakat tentang alamat tapi tidak melihat secara geografis.

lokasi penyebaran UMKM, letak wilayah dan penyebarannya dan memudahkan dalam mencari lokasi- 3.2. Analisis Pemecahan Masalah

lokasi UMKM yang dibutuhkan oleh Kepala Dinas.

\section{Tinjauan Pustaka}

\subsection{Sistem Informasi Geografis}

Berdasarkan analisis prosedur kerja yang ada, menurut penulis kurang efisien karena prosedur kerja yang ada di bidang UMKM saat ini hanya menampilkan data atribut saja, jadi penulis mencoba memberi pemecahan permasalahan seperti membuat Sistem Informasi Sistem Informasi Geografis adalah sistem computer Geografis yang mana sistem informasi geografis yang digunakan untuk memasukkan (capturing), tersebut dapat memberikan informasi berupa data atribut menyimpan, memeriksa, mengintegrasikan, dan data spasial.

memanipulasi, menganalisa, dan menampilkan datadata yang berhubungan dengan posisi-posisi Alur pengolahan data spasial.[7] dipermukaan bumi.[2] SIG merupakan sebuah sistem informasi yang didesain untuk bekerja dengan sumber data spasial. [3]

\subsection{Mapinfo}

Mapinfo merupakan salah satu perangkat lunak pemetaan (SIG) dekstop yang dikembangkan dan kemudian dipasarkan untuk memenuhi (seabgian besar) kebutuhan - kebutuhan di lingkungan bisnis. Perangkat SIG yang memungkinkan para penggunanya untuk memvisualisasi dan menganalisa data - data yang menjadi masukannya secara geografis lebih cepat dan menyediakan informasi yang diperlukan didalam proses pengambilan keputusan.[4]

\subsection{UMKM}

Usaha Mikro Kecil dan Menengah (UMKM) merupakan pelaku bisnis yang bergerak dibeberapa bidang usaha, yang menyentuh kepentingan masyarakat.[1]

\subsection{Data Spasial}

Data Spasial adalah data-data yang memiliki sistem koordinat geografis.[5]

\subsection{Data Atribut}

Data Atribut adalah data yang menggambarkan karakteristik suatu fitur permukaan bumi dalam bentuk kuantitatif dan kualitatif. Data atribut biasanya disajikan dalam bentuk data tabular.[5]

\subsection{UML}

UML (Unified Modeling Language) merupakan salah standar bahasa yang banyak digunakan di dunia industri untuk mendefinisikan requirement, membuat analisis dan desain, serta menggambarkan arsitektur dalam pemograman berorientasi objek. [6]

\section{Metodologi Penelitian}

\subsection{Analisis Prosedur Kerja}

Petugas kecamatan mendata UMKM disetiap kelurahan setelah data di peroleh dari kelurahan, petugas kecamatan melaporkan kepada pihak bidang UMKM lalu pihak bidang UMKM menginput data, jadi jenis laporannya hanya berupa nama, jenis usaha, dan alamat.

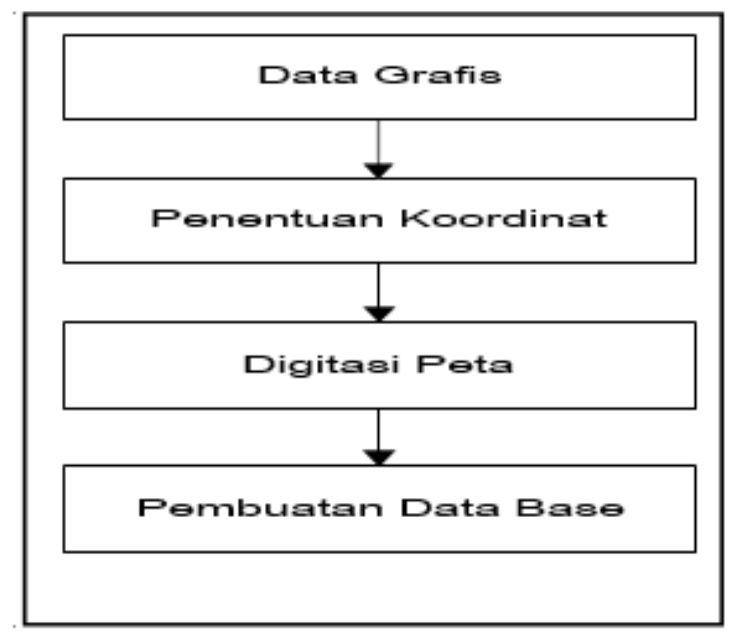

Gambar 1. Alur Pengolahan Data Spasial

Use Case Proyeksi Peta

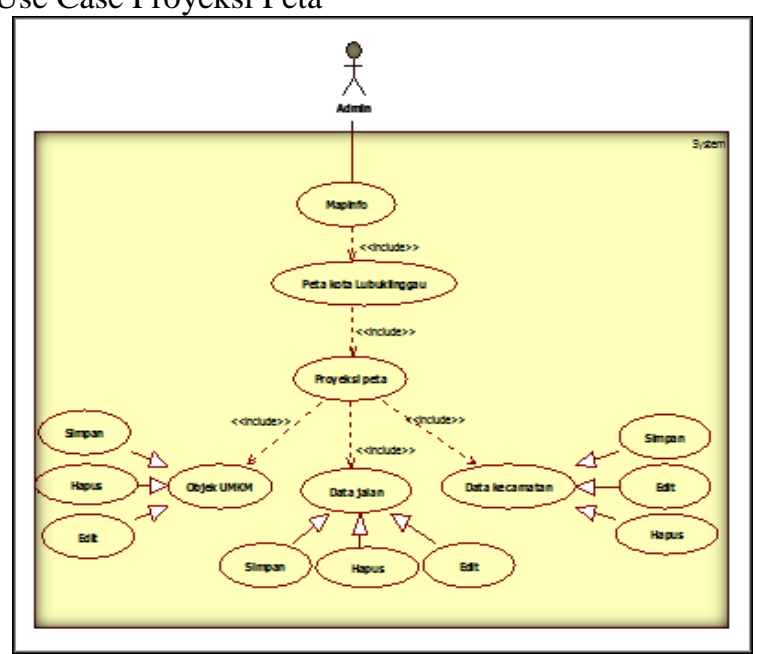

Gambar 2. Use Case Proyeksi Peta

\section{Hasil dan Pembahasan}

\subsection{Arsitektur Sistem}

Web Gis dikatakan adalah sebuah web mapping yang digunakan dalam browser tetapi bukan memetakan di dalam browser. Bentuk umum arsitektur berbasis peta di web dapat dilihat pada gambar 6. di bawah ini : 


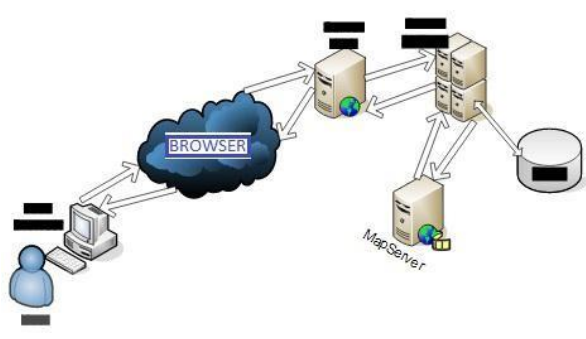

Gambar 3 Arsitektur Sistem [8]

Interaksi antara User dengan server berdasar request dan respon. Web browser pada user mengirim request ke server web. Karena server web tidak memiliki kemampuan pemrosesan peta, maka request berkaitan dengan pemrosesan peta akan diteruskan oleh server web ke server aplikasi dan Mapserver.

Tampilan home ini berisi tentang UMKM, Data Umkm, serta Visi dan Misi Umkm. Data UMKM, Visi dan Misi UMKM dapat di download pada halaman home ini, tampilah home dapat dilihat di gambar 4 di bawah ini :

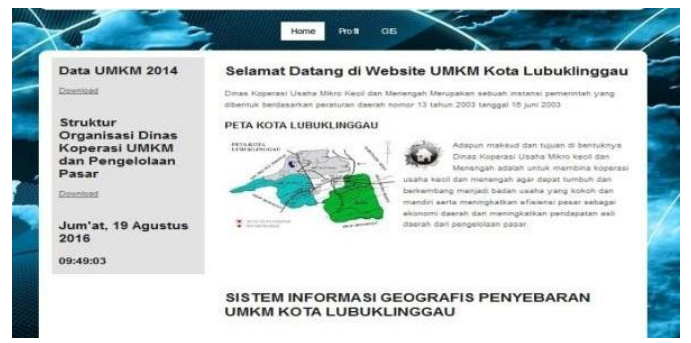

Gambar 4. Halaman Home

\subsection{Halaman Aplikasi}

Tampilan GIS

Pada tampilan gis berisikan gambar peta kota Lubuklinggau yang terdiri dari kecamatan, nama jalan dan objek UMKM. Pada tampilan GIS juga ada beberapa tools pendukung, yang nantinya di jelaskan oleh penulis di gambar berikutnya. Tampilan GIS dapat di lihat di gambar 5 di bawah ini :

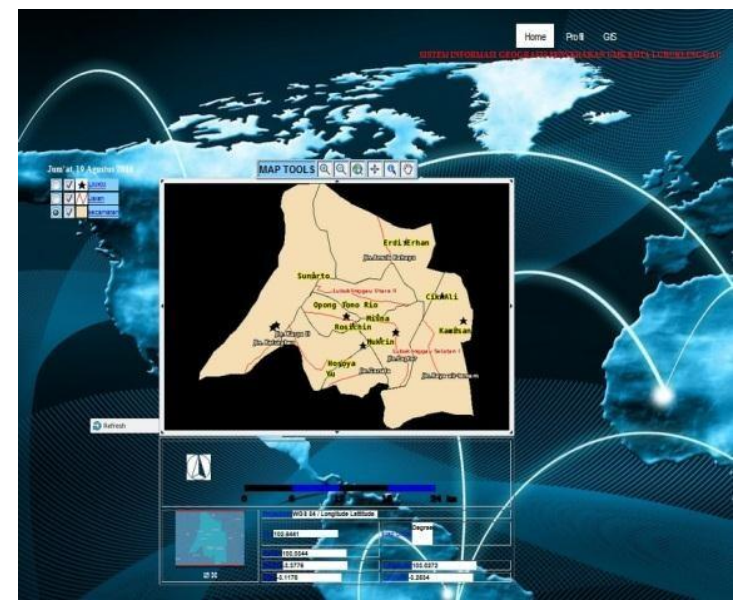

Gambar 5. Tampilan Gis
Pada tampilan menu, berisikan 3 tampilan, yang mana sudah di jelaskan pada gambar-gambar sebelumnya

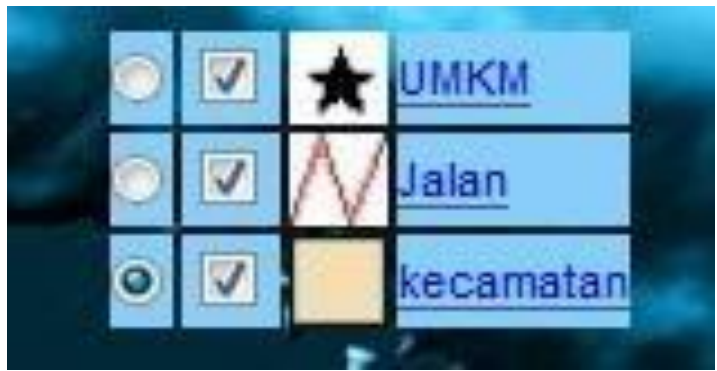

Gambar 6. Tampilan Legenda Pada GIS

Pada tampilan Legenda pada GIS memandu pengguna untuk menampilkan objek yang di inginkan, seperti keterangan gambar 6 .

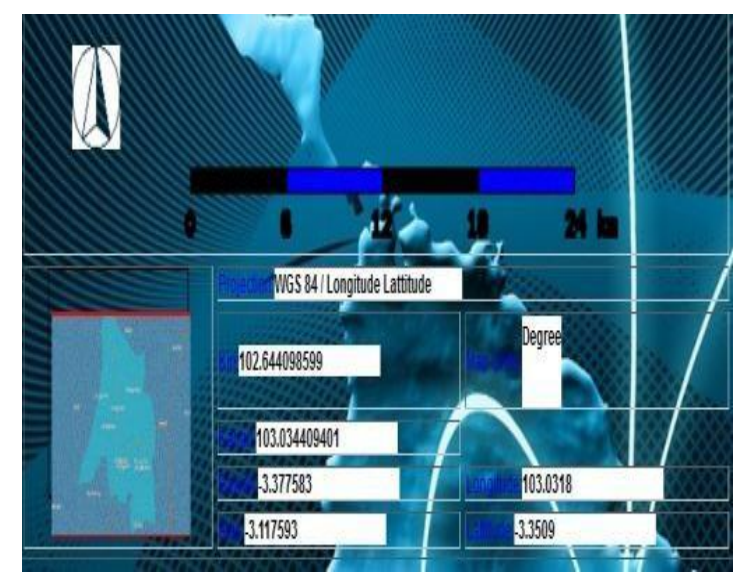

Gambar 7. Proyeksi pada GIS

1. Projection : Proyeksi yang di pakai dalam GIS UMKM di kota Lubuklinggau

2. Kiri: Sebagai batas kiri titik koordinat dalam tampilan GIS

3. Kanan : Sebagai batas kanan titik koordinat dalam tampilan GIS

4. Bawah : Sebagai batas Bawah titik koordinat dalam tampilan GIS

5. Atas : Sebagai batas atas titik koordinat dalam tampilan GIS

6. Longitude : Koordinat Lokasi kursor Latitude : Koordinat Lokasi kursor

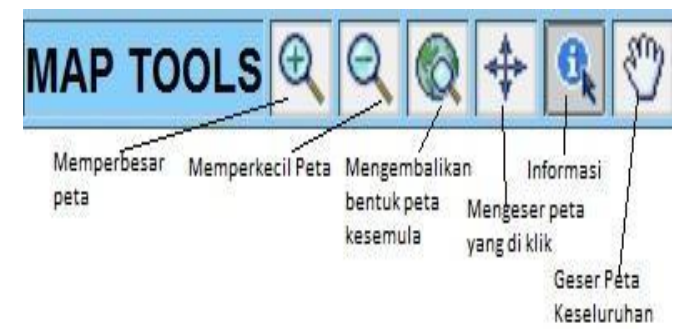

Gambar 8. Tampilan Map Tools 
Pada tampilan map tools bertujuan untuk memandu pengguna menggunakan pada tampilan GIS, yang mana nantinya dapat mempermudah pengguna dalam menjalankan Sistem Informasi Geografis penyebaran UMKM Kota Lubuklinggau seperti pada gambar 8.

\section{Kesimpulan}

\subsection{Simpulan}

Berdasarkan dari pembahasan, penulis dapat menarik kesimpulan sebagai berikut:

1. Dapat menggambarkan dan memberikan informasi mengenai penyebaran UMKM secara utuh di Kota Lubuklinggau sesuai dengan data atribut dan data spasial.

2. Dapat menampilkan informasi tentang penyebaran UMKM dengan sistem infomasi geografis berbasis web..

\subsection{Saran}

Adapun saran yang ingin penulis sampaikan adalah sebagai berikut:

1. Untuk Sistem informasi geografis penyebaran UMKM berbasis web di kota Lubuklinggau, dalam penelitian ini diharapkannya dapat dikembangkan lebih lanjut sesuai dengan perkembangan dan kebutuhan dari Kantor Dinas Koperasi, UMKM dan pengelolaan Pasar khusunya bidang UMKM.

2. Untuk pengembang selanjutnya dalam mencari objek UMKM dapat disediakan di perkembangan aplikasi berikutnya.
3. Untuk pengembangan selanjutnya program diharapkan bisa dengan mudah mencari UMKM berdasarkan kecamatan.

4. Untuk pengembang selanjutnya agar memperhatikan segi keamanan pada sistem yang dibangun.

\section{Daftar Rujukan}

[1] Undang Undang RI, Tahun 2008, Tentang Mikro, Kecil dan Menengah

[2] Apriani., I., 2012, Sistem Informasi Geografis Untuk Pemetaan Dan Pencarian Rumah Sakit Di Kota Yogyakarta, Jurnal Informatika Vol 6, No. 2, Hal. 687-699

[3] Asnawati.,Kusuma, G.P., 2011, Sistem Informasi Geografis (SIG) Fasilitas- Fasilitas yang ada di Kota Bengkulu Berbasis Web, Jurnal Media Infotama, Vol. 7 No. 2 September 2011, ISSN 1868-2680.

[4] Tjahjono, B., 2010, Pengembangan Aplikasi SIG Siteplan Perumahan Arcadia Daan Mogot, Forum Ilmiah, Vol. 7 No. 3 September 2010. Fakultas Ilmu Komputer Universitas Esa Unggul Jakarta.

[5] Madcoms., 2011, Aplikasi Web Database Dengan Dreamweaver Dan PHP- Mysql, ANDI., Yogyakarta.

[6] Shalahuddin., M. dan Rosa A.S., 2014. Rekayasa Perangkat Lunak: Bandung.

[7] Iqbal., M., Karya., G., 2012, Sistem Informasi Geografis Fasilitas Umum dan Sosial di Kabupaten Serang Menggunakan Mapserver dan Mysql Spasial, Jurnal Nasional Pendidikan Teknik Informatika, Vol. 1 No. 3, Desember 2012, ISSN 2089-8673.

[8] Hidayat., T., Tarmuji., A., 2013. Sistem Informasi Geografis untuk Pemetaan Lokasi Tk 'Aisyah Bustanul Athfal di 'Aisyah DIY. Jurnal Sarjana Teknologi Informatika Vol. 1 No. 2 Oktober 22013. Universitas Ahmad Dahlan: Yogyakarta. 